\title{
O BIBLIOTECÁRIO E A PERCEPÇÃO DE SEU ESPAÇO FÍSICO E AMBIENTAL
}

\author{
Selma Regina Ramalho Conte \\ Bibliotecária na Universidade Federal \\ do Paraná. Mestre em Comunicação e \\ Linguagens pela Universidade Tuiuti \\ do Paraná. \\ E-mail: selmaconte@gmail.com
}

\section{RESUMO}

A complexidade da natureza humana revela as diversas formas de relacionamento do homem com o mundo. A percepção do espaço físico e ambiental influencia os sentidos e altera as funções cognitivas. Essa preocupação está presente também dentro das bibliotecas, onde o bibliotecário tem seu próprio espaço físico e ambiental, comumente colocado em segundo plano, esquecendo-se de que a satisfação desse profissional reflete-se nos serviços prestados aos usuários. Isso posto, busca-se encontrar evidências da relação entre bibliotecários e o espaço físico e ambiental que lhes é destinado, com um levantamento na Biblioteca Digital Brasileira de Teses e Dissertações (BDTD); e, além disso, identificar, por meio de uma estratégia metacognitiva, pesquisas que abordem essa relação. Procura-se verificar, ainda, na Arquitetura, os detalhamentos sobre os espaços necessários para as áreas destinadas ao trabalho em bibliotecas e, na ergonomia, a concepção de ambientes responsivos às atividades desempenhadas, a partir de uma abordagem fenomenológica, que atenta aos modos pelos quais os sentidos são afetados pelo meio. Com isso, pretende-se obter argumentos para estruturar uma mudança de conceitos na formulação dos espaços para os bibliotecários, tendo como evidência a satisfação desses profissionais.

Palavras-chave: Bibliotecários - Percepção ambiental. Espaço físico e ambiental. Ambiente organizacional.

\section{THE LIBRARIAN AND THE PERCEPTION OF HIS ENVIRONMENTAL AND PHYSICAL SPACE}

\begin{abstract}
The complexity of human nature reveals several forms of man's relationship with the world. The perception of physical and environmental space influences the senses and alters cognitive functions. This concern is also present in the library, where the librarian has his own physical and environmental space commonly placed in the background, forgetting that their satisfaction is reflected in the services provided to users. Therefore, we seek evidences of the relationship between librarians and the physical and environmental space assigned to them
\end{abstract}


through a survey in the Brazilian Digital Library of Theses and Dissertations (BDTD), to identify, through a metacognitive strategy, researches that approach this relation. In the Architecture, the details about spaces required for the areas destined to work in libraries are also verified; and in ergonomics, the design of environments responsive to the activities performed, from a phenomenological approach, that looks at the ways in which the senses are affected by the environment. With this, we intend to get arguments to structure a change of concepts in the design of spaces for librarians taking as evidence the satisfaction of these professionals.

Keywords: Librarians - Environmental Perception. Physical and environmental space. Organizational environment.

\section{INTRODUÇÃo}

O homem é um ser que dentro de sua perspectiva relaciona-se com o mundo, percebendo-o de formas particulares, as quais variam de acordo com seu horizonte perceptivo. As diversas formas desse relacionamento revelam a complexidade da natureza humana, a capacidade, em maior ou menor grau, de convivência com os seus semelhantes, e o ambiente que o cerca. As percepções concebidas nessa experiência transpõem a racionalidade e permitem alcançar o sensível e o estético, sustentados pela imaginação e pela criatividade (MERLEAU-PONTY, 1999).

A percepção do espaço ambiental influencia os sentidos, alterando as funções cognitivas, intensificando-as ou reduzindo-as. A adaptação do ambiente construído para a realização de atividades que exijam desempenho tem buscado somar profissionais de diversas áreas, podendo otimizar a satisfação, buscando o aumento da produtividade, proporcionando melhores condições de trabalho e aproveitamento dos ambientes. Atualmente, essa preocupação está presente nos diversos setores produtivos; busca-se complementar a estrutura física integrando questões objetivas e subjetivas na adaptabilidade e conformidade do espaço, melhorando as atividades nele desenvolvidas.

Nesse sentido, reflete-se sobre uma forma de relação entre indivíduos e ambiente, especificamente sobre a percepção que bibliotecários têm quanto a seu espaço físico e ambiental dentro das bibliotecas, na delimitação de seu espaço, enquanto indivíduos, em relação a esse mesmo ambiente. Assim, toma-se como objetivo desta pesquisa buscar 
evidências da relação entre bibliotecários e o dimensionamento do espaço físico e ambiental que lhes é destinado.

A fim de justificar esta pesquisa, realizou-se um levantamento em teses e dissertações, na Biblioteca Digital Brasileira de Teses e Dissertações (BDTD), que abordassem, mesmo que minimamente, essa relação entre o bibliotecário e a percepção referente a seu espaço físico e ambiental. Determinou-se o uso da abordagem qualitativa que, neste caso, engloba aspectos da análise documentária, não do ponto de vista do indexador, mas por uma estratégia metacognitiva, como aponta Kato (1990, p. 108), ao definir um objetivo como condição específica de leitura, e ao monitorar a compreensão tendo em vista esse objetivo.

No ambiente de uma biblioteca, encontram-se dois atores: usuários e bibliotecários, com sua equipe de trabalho. Ao longo da história, os bibliotecários permaneceram como coadjuvantes, relegados a um segundo plano em seu próprio ambiente, esquecendo-se de que a satisfação desses profissionais reflete nos serviços prestados aos usuários. Diante da carência de pesquisas específicas dentro da Biblioteconomia, busca-se na Arquitetura, na metodologia fenomenológica, nos estudos da percepção e na ergonomia o entendimento dos indivíduos acerca dos espaços que ocupam, para a concepção dos ambientes.

Ser bibliotecário, atualmente, sugere ser um profissional flexível e adaptável às tecnologias de informação e comunicação, conhecer os mecanismos de busca de informações, informatizados ou não, e avaliar e antecipar as necessidades informacionais dos usuários. No contexto de atuação do bibliotecário, em que cada vez mais se depende de resultados, a transferência de conhecimentos está sendo vista como a grande força motriz do desenvolvimento intelectual; essa situação merece ser revista.

\section{A PERCEPÇÃO}

Para uma melhor compreensão acerca da percepção, recorre-se à fenomenologia, que descreve ou explica um fato ou uma ocorrência pela observação, facilitando retornar àquilo que foi negligenciado. É a fenomenologia que retrata a experiência perceptiva (CERBONE, 2014, p. 13, 159-160). Pelo entendimento dado por Merleau-Ponty, 
A percepção não é uma ciência do mundo, não é nem mesmo um ato, uma tomada de posição deliberada; ela é fundo sobre o qual todos os atos se destacam e ela é pressuposta por eles. 0 mundo não é um objeto do qual possuo comigo a lei de constituição; ele é o meio natural e o campo de todos os meus pensamentos e de todas as minhas percepções explícitas. (MERLEAU-PONTY, 1999, p. 6).

Nesse sentido, a percepção envolve aspectos intelectuais, emocionais, imagéticos e criativos, permitindo aos indivíduos relacionarem-se com o mundo, possibilitando outras experiências, outras vivências e novos contextos subjetivos (MARIN; KASPER, 2009, p. 268). A percepção constrói-se com a consciência (MERLEAU-PONTY, 1999, p. 46), a qual está sempre voltada para o mundo, e um não existe sem o outro. Essa intencionalidade atribui significados aos objetos percebidos. Ao entender a percepção como interpretação dos objetos, formas ou fenômenos que representam algo distinto de si mesmo, pode-se direcioná-la a todo e qualquer contexto, o mundo dado, o mundo vivido, e/ou o ambiente ao redor. Assim, os estímulos são fornecidos pela presença corporal, e o corpo atua como mediador do mundo, sendo o sujeito da percepção (MERLEAU-PONTY, 1999, p. 201, 303).

A constatação do espaço ambiental como objeto da percepção atribui um significado a esse espaço, um registro ativo dos estímulos. Dessa forma, essa percepção implica em estabelecer uma relação entre o ambiente e o que se percebe dele, uma experiência ativa (CERBONE, 2014, p. 17, 173-174). 0 espaço ambiental é descrito por Merleau-Ponty (1999, p. 50) como o lugar onde se vive ou se trabalha, arquitetonicamente organizado, que constitui um meio estético, ou psicológico, especialmente preparado para o exercício de atividades humanas, o ambiente social (NOVO, 2009; ORNSTEIN; BRUNA; ROMERO, 1995, p. 7). A percepção desse espaço é posicional, sendo o corpo o meio de comunicação com esse ambiente (CERBONE, 2014, p. 152; MERLEAU-PONTY, 1999, p. 136). Na experiência perceptiva, o indivíduo percebe-se a si mesmo e aos objetos no ambiente. Essa corporificação da percepção é caracterizada pela experiência em si mesma, um contínuo (CERBONE, 2014, p. 152, 178; SCHMID, 2005, p. 37).

Os estudos da Percepção Ambiental corroboram a busca pelo entendimento da percepção dos indivíduos acerca dos espaços que ocupam. São eles que sofrem mais de perto o impacto das sensações que o ambiente pode transmitir. Nessa perspectiva, Elali (1997, p. 353) argumenta que o espaço físico passa a ser considerado como espaço "vivencial", onde os indivíduos vivem e relacionam-se - o ambiente social proposto por 
Ornstein, Bruna e Romério (1995, p. 7) -, e acrescenta, ainda, aos aspectos construtivos e funcionais, as análises comportamentais e sociais, de ocupação, reinterpretação ou de modificação dos espaços. Na visão de Schmid (2005, p. 130), esse espaço vivido é finito, demarcado e heterogêneo, e pode estimular ou desencorajar os indivíduos ao interpretarem e perceberem indistintamente os ambientes, os quais, sob diferentes aspectos, denotam conforto, tanto pelo que são como pelo que representam; sentidos e ambientes comunicam-se, e essa interpretação pode ser consciente, ou não. Para tanto, os indivíduos consideram suas necessidades físicas (corporais), psicológicas, espirituais, sociais e culturais (SCHMID, 2005, p. 23-24, 324-325). Nessa instância, o ambiente influencia o estado de espírito dos indivíduos, como um efeito do ambiente físico em si.

Essa relação entre a conveniência do conforto ambiental e o seu enlevo propicia a formação do contínuo, pois "as relações entre as coisas ou entre aspectos das coisas são sempre mediadas por nosso corpo [...]." (SCHMIDT, 2005, p. 37-38, 45, 124). A amplitude do espaço físico, a posição de objetos, luzes e cores, a adequada iluminação no ambiente são importantes fatores que contribuem para a segurança, saúde, bem-estar e conforto. Fatores relacionados às condições de iluminação condicionam a percepção dos indivíduos face ao conforto visual, que se pode traduzir em fadiga, estresse e esforço físico. Os indivíduos respondem positivamente a locais amplos, arejados, com iluminação natural e cores estimulantes; essa percepção se dá no campo subjetivo, influenciando objetivamente o rendimento. 0 conforto ambiental pode remeter a estados psíquicos de maior ou menor concentração, transformar a percepção do indivíduo levando-o a experimentar mudanças de humor, acalmando-o ou excitando-o. Essas sensações podem ser percebidas pronta ou gradualmente, impregnando inconscientemente o indivíduo são as manifestações fisiológicas dos estímulos (MERLEAU-PONTY, 1999, p. 283-300).

A Arquitetura, tradicionalmente, tem considerado o ambiente sob um ponto de vista mais mecanicista, enfatizando as necessidades funcionais dos indivíduos, especificamente os confortos térmico, acústico e lumínico. Atualmente, as mudanças nesse sentido manifestam-se na compreensão das necessidades formais e estéticas, a fim de proporcionar um espaço agradável, de prazer e bem-estar, com proposições centradas no indivíduo ou no contexto social e ecológico, tornando o ambiente inspirador e melhorando o desempenho. Essas necessidades, diretamente ligadas às sensações provocadas pelo ambiente, relacionam-se com os valores dos indivíduos, e dependem de seus contextos social, subjetivo e cultural (ELALI, 1997, p. 351). Entende-se que as 
atividades desenvolvidas, o sistema funcional e a cultura organizacional influenciam na disposição do espaço físico, assim como a estrutura predial (NEUFERT, 2013, p. 247). A transposição dessas considerações para uma realidade dada defronta-se com um questionamento ainda sem resposta - a percepção do espaço físico e ambiental pelos bibliotecários dentro das bibliotecas.

\section{A PERCEPÇÃO DO ESPAÇO FÍSICO E AMBIENTAL DO BIBLIOTECÁRIO}

As bibliotecas, de modo geral, passam por mudanças decorrentes da incorporação de suportes e recursos informacionais, do aparecimento de novas tecnologias, bem como do aumento e diversidade de sua clientela, interna e externa. Essa é uma constante no histórico de toda biblioteca, haja vista os diversos relatos apresentados nos eventos de Biblioteconomia, Documentação e Ciência da Informação, nas teses e dissertações defendidas nos programas de pós-graduação e, além disso, nos livros e artigos publicados.

Para atender a essas demandas, as bibliotecas, muitas vezes, necessitam adequar a estrutura interna de gestão, aperfeiçoar produtos e serviços, além de construir e adaptar espaços físicos de modo a criar ambientes que possam ser utilizados por todos. Muitas bibliotecas, ainda hoje, funcionam em ambientes adaptados (GALBINSKI, 1993, p. 41), outras já ocupam prédios próprios, mas essa autonomia não as exime de readequações e reformas decorrentes de mudanças sociais, tecnológicas e conceituais (CUNHA, 2000, p. 78; MORAES; CRISTIANINI, 2004, p. 1-2; SANTORO, 2000, p. 2).

Ao falar em bibliotecas, a primeira imagem que vem à mente são seus acervos livros, teses e dissertações, periódicos, mapas, partituras, entre outros. As políticas de desenvolvimento de coleções ocupam-se da manutenção, crescimento e escopo desses acervos; os serviços de referência e informação dão assistência para uso dos recursos informacionais e das tecnologias disponíveis para tal; os processos técnicos incorporam e disponibilizam as aquisições; e os serviços de circulação atentam às questões relativas aos empréstimos, devoluções, reservas dos materiais e atendimento geral.

Para acomodar toda a estrutura de serviços oferecidos por uma biblioteca, é necessário, seja na construção de novos edifícios ou na adaptação de ambientes construídos, dimensionar os espaços para acervos, equipes de trabalho, e usuários, assim como estabelecer estimativas de crescimento. Para tanto, um programa de necessidades pode proporcionar os requisitos adequados à estrutura física necessária (MINUZZO, 2004, 
p. 389-390). A projeção interna dos ambientes de uma biblioteca funda-se em três elementos espaciais: acervo, locais de trabalho, e espaços de leitura. Essa ambientação deve ser motivadora, e deve incrementar a produtividade também dos indivíduos que trabalham em bibliotecas (GOMES, 2007, p. 47, 140; NEUFERT, 2013, p. 259). Entretanto, e de modo geral, todo o intento é direcionado à comunidade atendida pela biblioteca: os serviços que presta, os acervos que adquire, e sua organização física - os espaços de leitura e pesquisa, laboratórios, mobiliários, e outras dependências. Tudo é pensado em função de seus usuários. Bicheri (2008, p. 27-28) relata que o ambiente de uma biblioteca escolar deve ser

[...] atraente, acolhedor, envolvente e prazeroso: proporcionar conforto por meio de um local bem iluminado, ventilado, com uma clara sinalização/comunicação visual, mobiliado e decorado de acordo com o perfil de seus usuários [...]. (BICHERI, 2008, p. 27-28).

Outros tipos de bibliotecas encaixam-se nessa descrição, seja pública, comunitária, nacional ou universitária. Nesse conceito, cabe, ainda, a questão da acessibilidade. Com a publicação da NBR 9050 (ASSOCIAÇÃO BRASILEIRA DE NORMAS TÉCNICAS (ABNT), 2015), as bibliotecas têm procurado adaptar-se ou adequar-se ${ }^{1}$ ao escopo dessa norma 2 . De acordo com o conceito estabelecido por Ferrés (2006, p. 21), a biblioteca acessível

[...] é um espaço que permite a presença e proveito de todos, e está preparada para acolher a maior variedade de público possível para as suas atividades, com instalações adequadas às diferentes necessidades e em conformidade com as diferenças físicas, antropométricas e sensoriais da população. (FERRÉS, 2006, p. 21).

Aliada a essa normatização, o Design Universal, ou Design para Todos ${ }^{3}$, refere-se, entre outros, ao desenvolvimento e à avaliação de ambientes para serem usados por todos. Desse modo, os indivíduos com habilidades, necessidades e interesses variados,

\footnotetext{
${ }^{1}$ Ambiente adaptado: ambiente cujas características originais foram alteradas posteriormente para serem acessíveis. Ambiente adequado: ambiente cujas características foram originalmente planejadas para serem acessíveis (ASSOCIAÇÃO BRASILEIRA DE NORMAS TÉCNICAS, 2015).

2 Esta Norma estabelece critérios e parâmetros técnicos a serem observados quanto ao projeto, construção, instalação e adaptação do meio urbano e rural, e de edificações às condições de acessibilidade (ASSOCIAÇÃO BRASILEIRA DE NORMAS TÉCNICAS, 2015).

${ }^{3} 0$ conceito de design universal propõe uma arquitetura e um design mais centrados no ser humano e na sua diversidade (ASSOCIAÇÃO BRASILEIRA DE NORMAS TÉCNICAS, 2015).
} 
decorrentes, ou não, de envelhecimento, mobilidade reduzida ou deficiências, poderão ser beneficiados por ambientes acessíveis (MELO, 2006, p. 18).

São inúmeras as referências que mencionam as preocupações relativas aos espaços destinados aos usuários em bibliotecas. 0 relato de Santoro (2000) trata da influência da arquitetura de interiores nas bibliotecas, e indica a constante preocupação com o "conforto do usuário": o sistema de acesso ao acervo, o controle da circulação, a capacidade de acomodação, terminais de consulta, mobiliários confortáveis, liberdade e bem-estar, "um espaço onde os leitores se sentissem com vontade de permanecer" (SANTORO, 2000, p. 6). A pesquisa de Libardi et al. (2010, p. 8) aborda a modernização e a adequação do espaço físico da biblioteca, e constata a insatisfação dos usuários "quanto ao espaço para leitura, iluminação, comunicação visual, rede de computadores para acesso às bases de dados, climatização do ambiente". No trabalho desenvolvido por Medeiros, Puerta e Degasperi (2012, p. 2), sobre a aquisição de material bibliográfico, as autoras acreditam que o espaço para o usuário na biblioteca é uma questão primordial, "pois deve ser também um local agradável de leitura e lazer". Entende-se que as proposições de Ferrés (2006, p. 23), relacionadas à acessibilidade física, possam ser estendidas aos indivíduos que trabalham nas bibliotecas, mesmo tendo a autora usado a terminologia "usuário". Na Biblioteconomia, o termo "usuário" refere-se aos clientes externos atendidos pela biblioteca.

Os relatos mencionados indicam que as ações desenvolvidas nas bibliotecas estão, comumente, direcionadas aos usuários que as frequentam; o desencadeamento dessas ações tem como objetivo prover o controle e o acesso adequados às informações, tanto para pesquisa, ensino e lazer, como para o exercício da cidadania. A questão que se apresenta é a percepção que os bibliotecários têm de si próprios nos espaços físicos das bibliotecas, na delimitação de seu espaço ambiental, enquanto indivíduo - corpo que se comunica -, em relação a esse mesmo ambiente.

Atualmente, os bibliotecários não mais se restringem aos limites de um acervo. Cabe a esse profissional aliar aos procedimentos rotineiros da biblioteca outras habilidades e competências exigidas para entender e interpretar a informação, sua produção, captação, preservação e disseminação; para o uso de tecnologias da informação e da comunicação e sua concepção; para interagir em equipes multidisciplinares; para tomar ações administrativas; além de investir em sua própria qualificação e capacitação continuamente (SILVEIRA, 2008, 89). A justaposição desse papel social dos bibliotecários 
tem se consolidado com ações efetivas do Conselho Federal de Biblioteconomia e seus Conselhos Regionais, assim como das associações de classe e escolas de Biblioteconomia, com seus programas de graduação e pós-graduação. A profissão tem 50 anos de regulamentação, completados em 2015. Contudo, não se evidenciam preocupações com os indivíduos que trabalham nas bibliotecas, principalmente com relação ao dimensionamento do espaço físico e ambiental que lhes é destinado.

A literatura brasileira disponível sobre administração de bibliotecas, de modo geral, não aborda essa questão especificamente. No que tange a esse assunto, destaca-se Carvalho (1981, p. 22), que estabelece padrões mínimos de espaços para acervos, salas de leitura e de trabalho, sem distinção da tarefa a ser executada. Galbinski e Miranda (1993, p. 23, 34) indicam a elaboração de um programa de necessidades funcionais, especificando cada ambiente e o número de funcionários em cada local. A compilação de Costa ([2000], p. 2-3) aponta o que considerar para se calcular as áreas necessárias. A questão merece estudos mais aprofundados, haja vista "a universalização das bibliotecas nas instituições de ensino" (BRASIL, 2010).

\section{COLETA E ANÁLISE DE DADOS: TESES E DISSERTAÇÕES}

O levantamento realizado nesta pesquisa valeu-se de dados dos Programas de PósGraduação em Ciência da Informação e em Biblioteconomia, cadastrados na Plataforma Sucupira, obtidos pelo preenchimento do campo de pesquisa Área básica com o termo Ciência da Informação, e ao selecionar, no campo Situação do Programa, a opção em funcionamento, concomitantemente. Da mesma forma, repetiu-se a estratégia de busca com o termo Biblioteconomia.

Foram identificados 20 Programas de Pós-Graduação ${ }^{4}$, ofertados pela Fundação Casa de Rui Barbosa (FCRB), Universidade de Brasília (UnB), Universidade de São Paulo (USP), Universidade do Estado de Santa Catarina (UDESC), Universidade Estadual de Londrina (UEL), Universidade Estadual Paulista/Marilia (UNESP), Universidade Federal da Bahia (UFBA), Universidade Federal da Paraíba/João Pessoa (UFPA), Universidade

\footnotetext{
${ }^{4}$ A Universidade de São Paulo (USP) e a Universidade Federal de Minas Gerais (UFMG) são computadas duas vezes, pois, além dos Programas de Pós-Graduação em Ciência da Informação, oferecem, também, o Programa de Pós-Graduação em Gestão da Informação e o Programa de Pós-Graduação em Gestão \& Organização do Conhecimento, respectivamente.
} 
Federal de Minas Gerais (UFMG), Universidade Federal de Pernambuco (UFPE), Universidade Federal de Santa Catarina (UFSC), Universidade Federal de São Carlos (UFSCAR), Universidade Federal do Cariri (UFCA), Universidade Federal do Ceará (UFC), Universidade Federal do Estado do Rio de Janeiro (UNIRIO), Universidade Federal do Rio de Janeiro (UFRJ), Universidade Federal do Rio Grande do Norte (UFRN) e Universidade Federal Fluminense (UFF). Os programas da FCRB, USP (Programa de Pós-Graduação em Gestão da Informação), UFMG (Programa de Pós-Graduação em Gestão \& Organização do Conhecimento), UFSCAR, UFCA e UFC iniciaram suas atividades em 2016 e o programa da UFRN em 2015, portanto, não foram considerados neste levantamento.

Na busca pelas teses e dissertações dos 13 programas remanescentes, por meio do URL fornecido pela Plataforma Sucupira, que remete aos sítios dos respectivos Programas de Pós-Graduação, constatou-se que essa busca seria bem mais facilitada a partir da Biblioteca Digital Brasileira de Teses e Dissertações (BDTD), mantida pelo Instituto Brasileiro de Informação em Ciência e Tecnologia (IBICT). Optou-se por cotejar a lista das instituições encontradas na Plataforma Sucupira com as instituições participantes da BDTD, com exceção da UNIRIO, cujo levantamento das dissertações deu-se no próprio sítio do programa.

Ao pesquisar, individualmente, cada uma das instituições, constatou-se a seguinte distribuição: UnB com 126 teses em Ciência da Informação, 232 dissertações em Ciência da Informação e seis dissertações em Biblioteconomia e Documentação ${ }^{5}$. Dentre os programas que concedem títulos em Ciência da Informação, tem-se: USP com 94 dissertações e 57 teses; UEL com 31 dissertações; UNESP com 177 dissertações e 76 teses; UFBA com 148 dissertações e cinco teses; UFPA com 121 dissertações e uma tese; UFMG com 389 dissertações e 125 teses; UFPE com 57 dissertações; UFSC com 159 dissertações; UFRJ com 93 dissertações e 45 teses; e UFF com 73 dissertações e uma tese. A UNIRIO, que concede o título de mestre em Biblioteconomia, apresenta 44 dissertações, e a UDESC, que concede o título de mestre em Gestão da Informação, apresenta 22 dissertações. Esse levantamento inicial permitiu delimitar 2082 teses e dissertações.

\footnotetext{
${ }^{5}$ O Repositório Institucional UnB informa serem seis as dissertações em Biblioteconomia e Documentação. No entanto, uma delas informa, tanto em sua página de rosto como no termo de aprovação, conceder o título de mestre em Ciência da Informação, obtido em 2006. As demais foram defendidas nas décadas de 1980 e 1990. Disponível em:

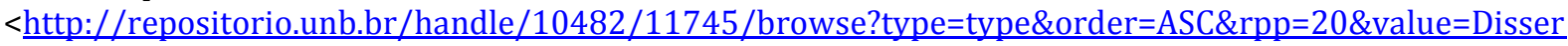
ta\%C3\%A7\%C3\%A30+\%2F+Dissertation>. Acesso em 04/11/2016.
} 
Numa segunda sondagem, procedeu-se à leitura dos títulos das teses e dissertações. Palavras que se sobressaíam indicavam a leitura dos resumos, tais como: autoimagem, características, competências, formação, identidade, liderança, perfil, profissão, profissional e trabalho. Nessa leitura, os aspectos abordados nas pesquisas e seus contextos elucidavam-se, tornando possível a seleção, ou não, da tese ou dissertação em questão.

Esse refinamento, e a leitura dos títulos associada à leitura dos resumos permitiram restringir o universo da pesquisa a seis dissertações (CAMPOS, 2008; CARVALHO, 2008; ROSA, 2007; SILVA, 2009a; SILVA, 2009b; SPUDEIT, 2010) e uma tese (WALTER, 2008). A pesquisa de Oliveira $(1980)^{6}$, indicada por Spudeit (2010, p. 55), não está disponível no Repositório Institucional UnB, portanto não foi analisada.

A análise, em si, examina aspectos relacionados ao ambiente físico identificados nas teses e dissertações anteriormente selecionadas. De modo geral, a abordagem dada ao ambiente está relacionada ao clima organizacional e à cultura corporativa. Tanto Campos (2008, p. 34) quanto Silva (2009b, p. 81) e Walter (2008, p. 142) concordam que cabe ao bibliotecário "interagir e agregar valor nos processos de geração, transferência e uso da informação em todo e qualquer ambiente" (BRASIL, 2001, p. 32). Nesse caso, cabe ao bibliotecário adequar-se. As decisões serão embasadas nas informações dadas pelo ambiente de trabalho (SILVA, 2009b, p. 51), assim como a construção de sua identidade profissional pode sofrer influências desse mesmo ambiente (SILVA, 2009b, p. 99; SPUDEIT, 2010, p. 32). A busca por um ambiente informacional bem-sucedido é inerente ao fazer bibliotecário, e esse sucesso infere mudanças, principalmente em ambientes mais tradicionais (CARVALHO, 2008, p. 16-17), uma vez que "já não se separa o profissional de seu ambiente de trabalho e da sociedade em que vive" (CARVALHO, 2008, p. 27). Ao certificar-se das tendências ambientais (SILVA, 2009b, p. 74), o bibliotecário, inserido "num contexto de normas e costumes previamente estabelecidos, intervém no ambiente, participa desse processo, influencia-o e é influenciado por ele" (SPUDEIT, 2010, p. 40).

No que diz respeito ao ambiente físico, especificamente, essas influências manifestam-se da mesma forma. Interagir em todo e qualquer ambiente significa, também, sofrer as influências das condições do ambiente de trabalho em relação ao

\footnotetext{
${ }^{6}$ OLIVEIRA, Zita Catarina Prates de. Um estudo da auto-imagem profissional do bibliotecário. $126 \mathrm{f}$. Dissertação (Mestrado) - Departamento de Biblioteconomia, Faculdade de Estudos Sociais, Universidade de Brasília, Brasília, 1980.
} 
conforto, à ergonomia, e à iluminação e ventilação adequadas (ROSA, 2007, p. 103; SILVA, 2009a, p. 69), sejam em ambientes tradicionais, ou "especializados e elitizados" (WALTER, 2008, p. 39). Nesse caso, cabe ao bibliotecário adaptar-se.

A pesquisa de Silva (2009a) é a que mais se aproxima das questões relacionadas ao espaço físico e ambiental, pois trata das percepções que os bibliotecários têm acerca de si mesmos (SILVA, 2009a, p. [6]). Para tanto, aborda a "inadequação do ambiente de trabalho" quanto à qualidade de vida, conforto ambiental, condições ergonômicas e materiais. Constata que essa inadequação afeta o desempenho profissional, bem como causa prejuízos à saúde (SILVA, 2009a, p. 69). Os participantes da pesquisa que consideraram o ambiente inadequado (70,8\%) apontaram o ruído, a iluminação, o mobiliário, a temperatura e a limpeza como os principais aspectos na falta de adequação. Essa precariedade ambiental é apontada como o fator que afeta o desempenho profissional por $84,7 \%$ dos participantes da pesquisa (SILVA, 2009a, p. 69-70). Silva (2009a, p. 87-88) questiona, ainda, a omissão por parte de bibliotecários quanto à inadequação do ambiente laboral, e a contradição que tal atitude evoca.

Diante dessa carência, faz-se necessário buscar soluções em outras áreas. É na Arquitetura, por exemplo, que se encontram os detalhamentos sobre espaços necessários para o trabalho em escritórios, que podem ser adaptados às áreas destinadas ao trabalho em bibliotecas (NEUFERT, 2013, p. 247); também na metodologia fenomenológica, que atenta aos modos pelos quais as coisas se manifestam, pela forma e estrutura dessas manifestações; nos estudos da percepção que buscam pelo entendimento que os indivíduos têm acerca dos espaços que ocupam; e na ergonomia, para a concepção de ambientes responsivos às atividades desempenhadas.

\section{CONSIDERAÇõES}

A percepção do espaço ambiental, em dado momento, é influenciada por múltiplos fatores que estimulam os sentidos. As sensações decorrentes desses estímulos fortalecem ou embotam a atenção provocando estados de animação e concentração ou, contrariamente, desânimo e dispersão. Esses estados anímicos podem ser percebidos prontamente ou na medida em que os sentidos são saturados. A atenção que ora se volta para esses efeitos sobre os indivíduos tem merecido destaque, devido ao fato de que as necessidades produtivas aumentaram nos diversos setores produtivos. 
Ao perceber-se no espaço ambiental e atribuir-lhe um significado, o bibliotecário toma consciência da relação corporal que tem com o ambiente e os estímulos que recebe no lugar que ocupa. Essa conscientização é como um despertar, um entendimento. Além da posição social do bibliotecário e seus espaços de atuação profissional, há um espaço físico e ambiental a ser considerado, uma vez que as bibliotecas têm grandes preocupações com seus acervos, e usuários, principalmente.

Após um levantamento inicial para identificar a relação do bibliotecário e a percepção do seu espaço físico e ambiental, percebe-se que seriam necessários estudos mais aprofundados na Biblioteconomia e Ciência da Informação, e em outras áreas, algumas já apontadas aqui, como, também, em outras fontes de pesquisa - eventos, periódicos e outros repositórios.

O encontro de determinadas circunstâncias - a formação acadêmica, as demandas sociais e organizacionais, e a definição do perfil profissional - influencia a percepção que o bibliotecário tem de si mesmo dentro do espaço físico e ambiental das bibliotecas. A falta de pesquisas voltadas especificamente à conscientização dos bibliotecários sobre esse espaço, com a visão centrada no próprio bibliotecário e adaptada para as transformações em curso no âmbito da profissão, torna necessária a pesquisa dessa relação, para que os bibliotecários possam influir-se em seu próprio ambiente, favorecendo o desempenho de suas funções.

\section{REFERÊNCIAS}

ASSOCIAÇÃO BRASILEIRA DE NORMAS TÉCNICAS. NBR 9050: acessibilidade a edificações, mobiliário, espaços e equipamentos urbanos. 3. ed. Rio Janeiro, ABNT, 2015. [162] p.

BICHERI, Ana Lúcia Antunes de Oliveira. A mediação do bibliotecário na pesquisa escolar face a crescente virtualização da informação. 197 f. Dissertação (Mestrado em Ciência da Informação) - Faculdade de Filosofia e Ciências, Universidade Estadual Paulista. 2008. Disponível em: <http://hdl.handle.net/11449/93713>. Acesso em: 21 jan. 2016.

BRASIL. Lei № 12.244, de 24 de maio de 2010. Dispõe sobre a universalização das bibliotecas nas instituições de ensino do País. Diário Oficial da República Federativa do Brasil, Brasília, DF, 24 maio 2010. Disponível em:

<http://www.planalto.gov.br/ccivil 03/ ato2007-2010/2010/lei/l12244.htm>. Acesso em: 08 nov. 2016.

BRASIL. Ministério da Educação. Conselho Nacional de Educação. Câmara de Educação Superior.

Diretrizes Curriculares Nacionais dos Cursos de Graduação de Filosofia, História, Geografia, Serviço Social, Comunicação Social, Ciências Sociais, Letras, Biblioteconomia, 
Arquivologia e Museologia. Diário Oficial da União, Brasília, DF, 03 abr. 2001. p. 32-34.

Disponível em:

<http://portal.mec.gov.br/cne/arquivos/pdf/CES0492.pdf>. Acesso em: 05 abr. 2015.

CAMPOS, Grazielle Noronha. Características e perfil dos bibliotecários das bibliotecas de instituições de ensino superior privadas do Distrito Federal e as expectativas dos empregadores. 133 f. Dissertação (Mestrado em Ciência da Informação) - Departamento de Ciência da Informação e Documentação, Universidade de Brasília, Brasília, 2008. Disponível em: $<$ http://repositorio.unb.br/bitstream/10482/1727/1/2008 GrazielleNoronhaCampos.pdf>. Acesso em: 03 nov. 2016.

CARVALHO, Fernando Cordeiro de. Educação e estudos de usuários em bibliotecas universitárias brasileiras: abordagem centrada nas competências em informação. $146 \mathrm{f}$. Dissertação (Mestrado em Ciência da Informação) - Departamento de Ciência da Informação e Documentação, Universidade de Brasília, Brasília, 2008. Disponível em:

<http://repositorio.unb.br/bitstream/10482/1697/1/2008fernandacordeirodecarvalho.pdf $>$. Acesso em: 03 nov. 2016.

CARVALHO, Maria Carmen Romcy de. Estabelecimento de padrões para bibliotecas universitárias. Fortaleza: UFC, 1981. 71 p.

CERBONE, David R. Fenomenologia. Petrópolis: Vozes, 2014. 292 p.

COSTA, Klytia de Souza Brasil Dias. Organização de bibliotecas: espaço físico. S. l.: SENAC/SICS, [2000]. [16 p.]

ELALI, Gleice Azambuja. Psicologia e Arquitetura: em busca do lócus interdisciplinar. Estudos de Psicologia, v. 2, n. 2, p. 349-362, 1997. Disponível em:

$<$ http://www.scielo.br/pdf/epsic/v2n2/a09v02n2.pdf>. Acesso em: 25 jan. 2016.

FERRÉS, Sofia Pérez. Acessibilidade física. In: PUPO, Deise Tallarico; MELO, Amanda Meincke; FERRÉS, Sofia Pérez. Acessibilidade: discurso e prática no cotidiano das bibliotecas. Campinas: UNICAMP, 2006. p. 21-32.

GALBINSKI, José; MIRANDA, Antonio L. C. Planejamento físico de bibliotecas universitárias. Brasília: PROBIB, 1993. 176 p.

GOMES, Samir Hernandes Tenório. Edifícios para bibliotecas universitárias: perspectivas e diretrizes a partir da avaliação-pós ocupação. 544 f. Tese (Doutorado em Arquitetura) Faculdade de Arquitetura e Urbanismo, Universidade de São Paulo, 2007. Disponível em: $<$ http://www.teses.usp.br/teses/disponiveis/16/16132/tde-29042010-105703/pt-br.php>. Acesso em: 22 jan. 2016.

KATO, Mary. 0 aprendizado da leitura. 3. ed. São Paulo: Martins Fontes, 1990.121 p.

LIBARDI, Leopoldina Mira Soares de Oliveira et al. Modernização e adequação do espaço físico da Biblioteca Central do campus de Ribeirão Preto/USP: relato de caso. In: SEMINÁRIO NACIONAL DE BIBLIOTECAS UNIVERSITÁRIAS, 16., 2010, Rio de Janeiro. Anais... Rio de Janeiro, 2010. p. 1-11. Disponível em: <http://www.sibi.ufrj.br/snbu2010/pdfs/posters/final 157.pdf>. Acesso em: 03 dez. 2010.

MARIN, Andréia Aparecida; KASPER, Kátia Maria. A natureza e o lugar habitado como âmbitos da experiência estética: novos entendimentos da relação ser humano - ambiente. Educação em 
Revista, Belo Horizonte, v. 25, n. 2, p. 267-282, ago. 2009. Disponível em: <http://www.scielo.br/pdf/edur/v25n2/12.pdf>. Acesso em: 30 nov. 2015.

MEDEIROS, Ana Paula Santulo Custódio de; PUERTA, Adriana Aparecida; DEGASPERI; Márcia Correa Bueno. Utilização dos orçamentos hierárquicos do Sistema Aleph no processo de aquisição de material bibliográfico pela biblioteca da UNESP Campus de Rio Claro. In: SEMINÁRIO NACIONAL DE BIBLIOTECAS UNIVERSITÁRIAS, 17., 2012, Gramado. Anais... Gramado: UFSC, 2012. p. 1-12. Disponível em: <http://www.snbu2012.com.br/anais/pdf/4QTF.pdf>. Acesso em: 23 jan. 2016.

MELO, Amanda Meincke. Acessibilidade e design universal. In: PUPO, Deise Tallarico; MELO, Amanda Meincke; FERRÉS, Sofia Pérez. Acessibilidade: discurso e prática no cotidiano das bibliotecas. Campinas: UNICAMP, 2006. p. 17-20.

MERLEAU-PONTY, Maurice. Fenomenologia da percepção. São Paulo: Martins Fontes, 1999. 662 p.

MINUZZO, Liziane Ungaretti. Programa de necessidades para a nova sede da biblioteca pública do estado do Rio Grande do Sul. Em Questão, Porto Alegre, v. 10, n. 2, p. 389-403, jul./dez., 2004. Disponível em: <http://seer.ufrgs.br/index.php/EmQuestao/article/view/103/61 >. Acesso em: 22 jan. 2016.

MORAES, J. S.; CRISTIANINI, G. M. S. Planejamento da construção de edifícios para bibliotecas: requisitos básicos. In: SEMINÁRIO NACIONAL DE BIBLIOTECAS UNIVERSITÁRIAS, 13., 2004, Natal. Anais... Natal: UFRN, 2004. 1 CD-ROM.

NEUFERT, Ernst. Arte de projetar em arquitetura: princípios, normas, regulamentos sobre projeto, construção, forma, necessidades e relações espaciais, dimensões de edifícios, ambientes, mobiliário, objetos tendo o homem como unidade de medida e seu objetivo: manual para arquitetos, engenheiros, estudantes, professores, construtores e proprietários. 18. ed. totalmente renov. e atual. São Paulo: G. Gili, 2013. 567 p.

NOVO Dicionário Eletrônico Aurélio. 2009.

ORNSTEIN, Sheila Walbe; BRUNA, Gilda Collet; ROMERO, Marcelo de Andrade. Ambiente construido \& comportamento: a avaliação pós-ocupação e a qualidade ambiental. São Paulo: Nobel: FUPAM, 1995.

ROSA, Regina Célia. Caracterização do trabalho do bibliotecário no campo jurídico em Belo Horizonte. 156 f. Dissertação (Mestrado em Ciência da Informação) - Escola de Ciência da Informação, Universidade Federal de Minas Gerais, Belo Horizonte, 2007. Disponível em: $<$ http://www.bibliotecadigital.ufmg.br/dspace/bitstream/handle/1843/BUBDA35GWB/disserta o regina c lia rosa.pdf?sequence=1>. Acesso em: 07 nov. 2016.

SANTORO, M. I. A influência da arquitetura de interiores na organização e uso de bibliotecas: o caso da UNICSUL. In: SEMINÁRIO NACIONAL DE BIBLIOTECAS UNIVERSITÁRIAS, 12., 2000, Florianópolis. Anais... Florianópolis: UFSC, 2000. p. 1-16. Disponível em: <http://snbu.bvs.br/snbu2000/docs/pt/doc/t029.doc>. Acesso em: 25 jan. 2012.

SCHMID, Aloísio Leoni. A idéia de conforto: reflexões sobre o ambiente construído. Curitiba: Pacto Ambiental, 2005. 339 p. 
SILVA, Alda Lima. A auto-imagem do profissional bibliotecário na sociedade. $112 \mathrm{f}$. Dissertação (Mestrado em Ciência da Informação) - Instituto de Ciência da Informação, Universidade Federal da Bahia, Salvador, 2009a. Disponível em:

$<$ https://repositorio.ufba.br/ri/bitstream/ri/7926/1/Dissertacao completa\%20AldaSilva.pdf>. Acesso em: 07 nov. 2016.

SILVA, Janaina Costa. 0 estilo de liderança dos bibliotecários de Brasília. 169 f. Dissertação (Mestrado em Ciência da Informação) - Departamento de Ciência da Informação e Documentação, Universidade de Brasília, Brasília, 2009b. Disponível em: $<$ http://repositorio.unb.br/bitstream/10482/4944/1/2009 JanainaCostaSilva.pdf $>$. Acesso em: 03 nov. 2016.

SILVEIRA, Fabrício José Nascimento da. O bibliotecário como agente histórico: do "humanista" ao “Moderno Profissional da Informação. Inf. \& Soc.: Est., João Pessoa, v. 18, n. 3, p. 83-94, set./dez. 2008. Disponível em:

$<$ http://www.ies.ufpb.br/ojs/index.php/ies/article/view/1873/2275>. Acesso em: 23 jan. 2016.

SPUDEIT, D. F. A. O. 0 processo de socialização na construção da identidade dos bibliotecários em Santa Catarina. 121 f. Dissertação (Mestrado em Ciência da Informação) Centro de Ciências da Educação da Universidade Federal de Santa Catarina, Florianópolis, 2010. Disponível em:

$<$ https://repositorio.ufsc.br/bitstream/handle/123456789/94404/288188.pdf?sequence=1\&is Allowed $=y>$. Acesso em: 07 nov. 2016.

WALTER, Maria Tereza Machado Teles. Bibliotecários no Brasil: representações da profissão. 2008. 345 f. Tese (Doutorado em Ciência da Informação) - Universidade de Brasília, Brasília, 2008. Disponível em: <http://repositorio.unb.br/handle/10482/5288>. Acesso em: 03 nov. 2016.

Recebido em: 10 de janeiro de 2017 Aceito em: 22 de novembro de 2017 